\title{
David Cosgrove Obituary
}

David Owen Cosgrove, "Doc" to his friends, of Wimbledon, London, UK, lost his battle with cancer on Tuesday the $16^{\text {th }}$ of May 2017, at St. Raphael's Hospice, North Cheam, London. Professor Cosgrove died two days short of his $79^{\text {th }}$ birthday. He was born on the $18^{\text {th }}$ of May 1938 in Nairobi, Kenya, the son of Alfred Owen Cosgrove (born 1901 South Africa, BSc Electrical Engineering, Cape Town University, died Nairobi 1962) and Kathleen Mary Cosgrove (nee Carlisle, born South Africa 1908, secretary, died Nairobi 1967). He is survived by his brother John Philip Carlisle Cosgrove (born Nairobi 1945), financial accountant and retired United Nations Official, and by his partner Zhen Li (Jason).

David went to a number of good schools in Kenya, culminating in his secondary education at the Duke of York High School, where he was Head Boy. This is now known as Lenana School (https://en.wikipedia.org/wiki/ Lenana_School), situated outside Nairobi at the foot of the Ngong Hills near the village of Karen, named after Karen Blixen author of "Out of Africa" (details: http://www. mccrow.org.uk/eastafrica/duke\%20 of\% 20york\%20school/Duke\%20of\%20York\% 20School.htm and http://www.oldyorkist. com/). The 1985 film of the same name gives a good impression of the surrounding countryside that formulated David's early years.

When David was at home in Nairobi for school holidays, he and his brother John would go on various trips to game parks and the coast. John recalls that this was where he learnt of David's strong interest in, and great deal of knowledge of, almost everything, but in particular nature: "David had a major positive influence on my life in the appreciation of flora and fauna. He also taught me about classical music, a great love of his."

David graduated from high school in 1955 with "A levels", ready for university entrance. His parents had the foresight to understand that David was exceptionally gifted and they supported his wish to apply to Oxford University, with his mother working to pay for his fees, which were then as now considerable for an "overseas" student. At age 17 David left Kenya, passed the Oxford University entrance examination and went on to obtain a BA in Physiology from Oxford (1961) and subsequently a BM BCh (Bachelor of Medicine, Bachelor of

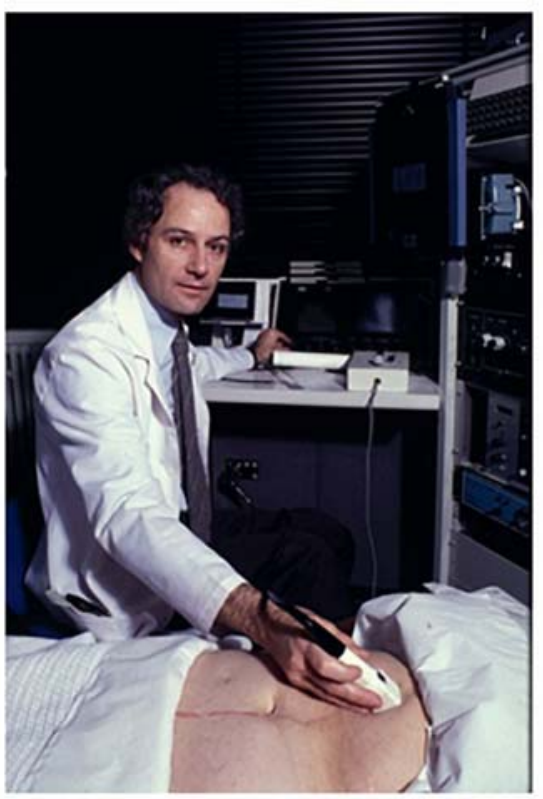

David (circa 1983), holding the probe of a radically new real-time phased array abdominal ultrasound scanner (code named at EMI CRL as the "Falcon"), a prototype being evaluated in comparison with the home-built ceiling-mounted static B-scan system "Icarus" (probe out of view, control console on the right of the picture). 
Surgery - Medicinae Baccalaureus, Baccalaureus Chirurgiae) at St. George's Hospital Medical School in Tooting, London (1963). After working at several hospitals in London he returned to Kenya and practiced medicine at the Jomo Kenyatta Hospital in Nairobi (1971). He soon understood that he would be happier and could make a more significant contribution to Medicine in England, the country to which he returned and in which he subsequently remained for the rest of his life, working in medical ultrasound to achieve world renowned standing and advancing his speciality in an unprecedented manner.

The ensuing list of honours and accomplishments in David's astonishingly successful career are extensive, suffice to say that David's contributions were immense. The main areas where he substantially advanced the clinical role of "radiological" (i.e. non-obstetric) ultrasound, included improved understanding of the basic mechanisms of the ultrasound image-forming process and of Doppler ultrasound, developed and evaluated ultrasound "tissue characterisation" methods, developed and greatly advanced many clinical applications of microbubble (contrast) enhanced ultrasound, and demonstrated how to apply ultrasound elastography to clinical diagnosis.

He became a Member of the Royal College of Physicians in 1967 and a Fellow in 1990. He obtained an MSc in Nuclear Medicine, University of London, in 1975. A key moment in David's career, and the career of many others, was when he started as a Research Fellow in the Department of Nuclear Medicine at the Royal Marsden Hospital under V.R. (Ralph) McCready, in collaboration with C.R. (Kit) Hill in the Institute of Cancer Research, who together had a Medical Research Council programme grant to develop and evaluate investigative ultrasound methods. At that time in the Royal Marsden Hospital, patients were scanned with ultrasound in the Nuclear Medicine Department as interest in ultrasound started there, prior to any radiology interest, whilst still an emerging diagnostic modality in cancer medicine. David moved this work forward in his characteristically professional way. He stayed in this area of medicine and research for the remainder of his career, making such an important and sustained contribution to investigative radiology that most people assumed he was a radiologist. In 1998 the Royal College of Radiologists recognised this by inviting him to become an Honorary Fellow.

The team at the Institute of Cancer Research and Royal Marsden Hospital at this time built its own ultrasound scanners for clinical use (with the new "grey scale" imaging method), and had a collaboration with EMI Central Research Laboratories. At the time, EMI was the world's largest producer of vinyl records, but had also pioneered airborne radar, commercialised television and developed the $x$-ray CT scanner from the Nobel Prize winning invention that Godfrey Hounsfield had made while working there. During the late " $70 \mathrm{~s}$ and early ' $80 \mathrm{~s}$ EMI were also a leader in medical ultrasound. They had built, in part with David's advice, one of the early commercial phased array abdominal ultrasound scanners.

He had a deeply intellectual approach, and a tremendous curiosity, particularly about the ultrasound physics related to his many observations of imaging phenomena in clinical ultrasound practice, and how best to explain them. At joint clinical-physics meetings he would bring (initially) Polaroid photographs and (subsequently) video tapes of recent cases which he used to challenge physicists, to find an explanation of some observed phenomenon.

In 1993, after a tremendously successful period at the Royal Marsden Hospital (Consultant in Nuclear Medicine and Ultrasound from 1977), David moved to the Royal Postgraduate Medical School at the Hammersmith Hospital. This later became a part of the Imperial College School of Medicine, where he was awarded a personal chair as Professor of Clinical Ultrasound. He may have been happier with the moniker 'Professor of Bubbles'; during this time he was at the forefront of developments in the use of microbubble contrast agents in ultrasound imaging. He co-founded the International Contrast Ultrasound Society (ICUS) in 2008. He was an active and highly valued contributor to weekly Engineering and Physics ultrasound meetings until very recently.

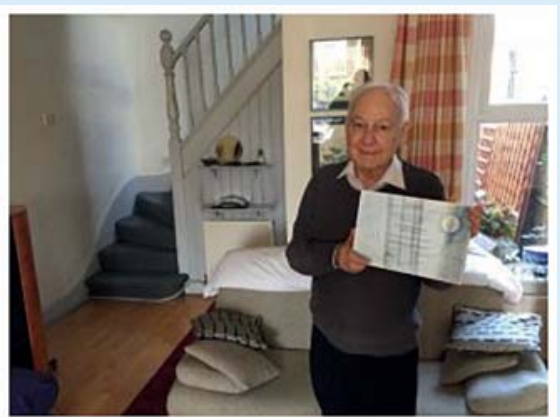

The Board of Delegates honoured David as an EFSUMB Fellow in March this year.

After David 'retired' in 2004, becoming Emeritus Professor at Imperial College, he took a new role as a Senior Research Investigator at King's College Hospital, and generously continued weekly clinical sessions at the Hammersmith and Charing Cross Hospitals. At King's, he immersed himself into paediatric use of microbubble contrast to establish once again in his career a new direction for ultrasound. He was actively publishing new reports in this field at the time of his death. At Imperial he also remained an active senior investigator, bringing together physicists, engineers, radiologists and clinical teams with his insight for studies of clinical applications of new ultrasound technologies.

Although David published more than 200 peer reviewed research articles and 30 teaching books/book chapters over his career, teaching is something for which David will be particularly remembered, much conducted at a very personal level. His talent for clarity, when summarising or explaining anything, combined with his gentleness and patience, made him a magnet for trainees from around the world. Over the decades he inspired a small army of individuals, both clinical and technical, many of whom have gone on to have successful careers and take up leadership roles in clinical, academic and commercial institutions. This built him a world-wide network of friends who held him in great esteem and with considerable affection, in Europe, Japan, North America, South America, India, China, Russia, the Middle Eastern and many other countries. He held visiting professorships in Philadelphia USA, Wenzhou China and Hangzhou China, was one of the world's most sought-after invi- 
ted speakers at international conferences and held honorary memberships in many national and regional ultrasound societies.

David's knowledge, experience and clear thinking meant that he was often asked to take advisory and consultative positions, even in fields outside of his own such as high intensity focussed ultrasound. He was Director, Secretary and Vice President of the International Contrast Ultrasound Society, advisor to NICE and various grant giving authorities, and a member of many editorial boards of journals and expert working groups. A particularly important contribution, which continued throughout his retirement, was his role in advising companies. His advice for product improvement was invaluable, and in return he would be able to work with the very latest and novel products for evaluation and research study. Through his diplomacy and visibly open integrity he was able to engage simultaneously in this way with many companies.

David possessed a deep intellect and was driven by an insatiable curiosity. He also exhibited an intellectual generosity that helped many people, and this was one of the attributes that won him so many friends. He was the "go to" person for objective and thoughtful advice on a great many topics. A modest, kind and gentle person, he valued quietly continuing his work, listening to music, studying the arts and nature (including diving), cooking and spending time with his friends.

A giant of the medical ultrasound world has passed away, unique in so many ways and an inspiration to generations of ultrasound practitioners across the world.

Jeff Bamber, Robert Eckersley, Chris Harvey, Adrian Lim, Paul Sidhu, Meng Xing Tang 